\title{
Netupitant/Palonosetron: A Review in Chemotherapy-Induced Nausea and Vomiting
}

\author{
Matt Shirley ${ }^{1}$
}

Accepted: 15 June 2021 / Published online: 22 July 2021

(c) Springer Nature 2021, corrected publication 2021

\begin{abstract}
Netupitant/palonosetron (NEPA; Akynzeo ${ }^{\circledR}$ ), available in oral and intravenous (IV) formulations, is a fixed-dose combination of the neurokinin 1 (NK1) receptor antagonist netupitant (or the prodrug, fosnetupitant, in the IV formulation) and the secondgeneration serotonin $3\left(5-\mathrm{HT}_{3}\right)$ receptor antagonist palonosetron. Administered as a single dose, (fos)netupitant/palonosetron (in combination with dexamethasone) is indicated for the prevention of acute and delayed chemotherapy-induced nausea and vomiting (CINV) in adults. In clinical trials, (fos)netupitant/palonosetron plus dexamethasone was associated with high complete response rates (no emesis and no rescue medication) in the acute, delayed and overall phases in patients receiving highly or moderately emetogenic chemotherapy, with efficacy maintained over multiple cycles. Further, oral netupitant/ palonosetron was found to be superior to palonosetron and non-inferior to aprepitant plus granisetron in preventing CINV in individual trials. Both the oral and IV formulations of the drug combination are well tolerated. The fixed-dose combination is concordant with guideline recommendations and provides a simple and convenient option for prophylaxis against acute and delayed CINV in patients receiving highly or moderately emetogenic chemotherapy.
\end{abstract}

\section{Plain Language Summary}

Chemotherapy-induced nausea and vomiting (CINV) is a common problem during cancer treatment. Netupitant/palonosetron (NEPA; Akynzeo ${ }^{\circledR}$ ) is a fixed-dose combination of two drugs (netupitant, a neurokinin 1 receptor antagonist; and palonosetron, a serotonin 3 receptor antagonist) which target two different signalling pathways involved in the induction of vomiting. Approved for use in the prevention of acute and delayed CINV in adults, netupitant/palonosetron is given orally or via intravenous infusion as a single dose prior to chemotherapy. In clinical trials, high proportions of patients who received netupitant/palonosetron (used in combination with the corticosteroid dexamethasone) prior to chemotherapy reported no vomiting, no requirement for rescue medication, and no significant nausea in the 5 days post chemotherapy. Both the oral and intravenous formulations of the drug combination are well tolerated. In conclusion, netupitant/palonosetron is a simple, convenient and effective drug combination for the prevention of acute and delayed CINV in patients receiving chemotherapy that has a moderate to high potential to cause nausea and vomiting.

\section{Introduction}

Digital Features for this Adis Drug Evaluation can be found at https://doi.org/10.6084/m9.figshare.14782410

The manuscript was reviewed by: $R$. A. Clark-Snow, Oncology Supportive Care Consultant, Kansas, USA; J. M. du Plessis, Faculty of Health Sciences, North-West University, Potchefstroom, South Africa; A. Maeda, Department of Pharmacy, Aichi Cancer Center Hospital, Nagoya, Aichi, Japan.

Matt Shirley

demail@springer.com

1 Springer Nature, Private Bag 65901, Mairangi Bay, Auckland 0754, New Zealand
Chemotherapy-induced nausea and vomiting (CINV) is mediated by an interaction of neurotransmitter pathways, including serotonin and substance $P$ pathways [1]. Guidelines for the prevention of CINV recommend that patients scheduled to receive highly emetogenic chemotherapy (HEC) or moderately emetogenic chemotherapy (MEC) should be given combination prophylaxis with drugs targeting different pathways [2-5]. Different options for use in CINV prophylaxis include the dopamine and serotonin 2 $\left(5-\mathrm{HT}_{2}\right)$ receptor antagonist olanzapine, neurokinin 1 (NK1) receptor antagonists [e.g. (fos)aprepitant, (fos)netupitant, 
Netupitant/palonosetron: clinical considerations in CINV

A fixed-dose combination of the NK1 receptor antagonist netupitant and the 5- $\mathrm{HT}_{3}$ receptor antagonist palonosetron

Available in oral and IV formulations; administered as a single dose prior to chemotherapy

Efficacious in the prevention of acute and delayed CINV, with efficacy maintained over multiple chemotherapy cycles

Both formulations are well tolerated

rolapitant], serotonin $3\left(5-\mathrm{HT}_{3}\right)$ receptor antagonists (e.g. dolasetron, granisetron, ondansetron, palonosetron) and corticosteroids (typically dexamethasone).

Netupitant/palonosetron (NEPA; Akynzeo ${ }^{\circledR}$ ) is a fixeddose combination of the NK1 receptor antagonist netupitant and the second-generation $5-\mathrm{HT}_{3}$ receptor antagonist palonosetron $[6,7]$, with the rationale that the convenience of administering the two drugs in a fixed combination (as a single dose) has the potential to improve adherence to CINV prevention guidelines [8]. Netupitant/palonosetron is approved in the USA [6] and the EU [7] for use (in combination with dexamethasone) in the prevention of CINV in adults, and is available in oral and, more recently, intravenous (IV) formulations (with fosnetupitant, a water-soluble prodrug of netupitant, used in the IV formulation). This article reviews therapeutic efficacy and tolerability data relating to the use of (fos)netupitant/palonosetron in the prevention of CINV, and also summarises pharmacological data relating to the drug combination.

\section{Pharmacodynamic Properties}

Netupitant, a potent and selective NK1 receptor antagonist, acts in the prevention of nausea and vomiting by inhibiting the interaction between substance P and NK1 receptors, thereby disrupting signalling that has been linked with delayed emesis [6, 7]. Six hours after the administration of a single dose of netupitant $300 \mathrm{mg}$ in healthy male subjects, NK1 receptor occupancy was $\geq 90 \%$ in several regions of the brain (including the occipital cortex, the frontal cortex and the striatum) [9]. Monitoring up to $96 \mathrm{~h}$ showed a slow decline in receptor occupancy.

Palonosetron, a highly potent and highly selective $5-\mathrm{HT}_{3}$ receptor antagonist [10], primarily acts by inhibiting serotonin signalling, which is involved in the development of acute emesis [6, 7]. In addition, palonosetron displays activity in the prevention of delayed emesis [11]. Not only does palonosetron bind $5-\mathrm{HT}_{3}$ receptors with higher affinity than the first generation $5-\mathrm{HT}_{3}$ receptor antagonists ondansetron and granisetron [10], in vitro studies have shown that, in contrast to ondansetron and granisetron, palonosetron exhibits allosteric binding and positive cooperativity when binding to the $5-\mathrm{HT}_{3}$ receptor [12]. Again in contrast to ondansetron and granisetron, there is evidence that palonosetron inhibits cross-talk between the NK1 and 5- $\mathrm{HT}_{3}$ receptor pathways, a characteristic that is proposed to be responsible (at least in part) for the observed effects of palonosetron in preventing delayed emesis [13].

There is also evidence that netupitant and palonosetron act synergistically, with enhanced inhibition of the substance P-mediated effects at NK1 receptors when both antagonists are present [14]. Mechanistic studies show that netupitant [15] and palonosetron [16] trigger internalisation of the NK1 and 5-HT 3 receptors, respectively. Furthermore, netupitant-triggered NK1 receptor internalisation is enhanced in the presence of palonosetron in a $5-\mathrm{HT}_{3}$ receptor-dependent manner [15].

\section{Pharmacokinetic Properties}

(Fos)netupitant/palonosetron is a fixed-dose combination comprised of netupitant $300 \mathrm{mg}$ and palonosetron $0.5 \mathrm{mg}$ in the oral formulation and fosnetupitant $235 \mathrm{mg}$ and palonosetron $0.25 \mathrm{mg}$ in the IV formulation [6, 7]. Unless otherwise indicated, these are the doses used for the data discussed in this section. Fosnetupitant is a water-soluble, phosphorylated prodrug of netupitant [17].

Netupitant and palonosetron pharmacokinetics are not altered to any clinically relevant extent under co-administration [6, 7]. Administration of netupitant/palonosetron with food or under fasting conditions has no clinically relevant effects on netupitant and palonosetron exposure $[6,7,18]$.

\section{1 (Fos)netupitant Pharmacokinetics}

Following oral administration of netupitant/palonosetron, measurable concentrations of netupitant are attained in $15 \mathrm{~min}$ to $3 \mathrm{~h}$, with netupitant reaching a maximum plasma concentration $\left(\mathrm{C}_{\max }\right)$ of $\sim 400-500 \mathrm{ng} / \mathrm{mL}$ in $\sim 4-5 \mathrm{~h}[6,7]$. Netupitant exposure increases greater than dose proportionally over the dose range of $10-300 \mathrm{mg}$ and dose proportionally from $300 \mathrm{mg}$ to $450 \mathrm{mg}$.

Following IV administration of fosnetupitant/palonosetron, fosnetupitant is rapidly converted to netupitant via metabolic hydrolysis $[6,7]$. In cancer patients, fosnetupitant and netupitant each reach $\mathrm{C}_{\max }(3478 \mathrm{ng} / \mathrm{mL}$ and $590 \mathrm{ng} /$ $\mathrm{mL}$, respectively) near the end of the 30-min infusion, with the fosnetupitant concentration decreasing to $<1 \%$ of $\mathrm{C}_{\max }$ 
within $30 \mathrm{~min}$ of completion of the infusion. Over the fosnetupitant dose range of $17.6-353 \mathrm{mg}$, systemic exposure increases dose proportionally.

Netupitant has a large volume of distribution (mean $\mathrm{V}_{\mathrm{z}} / \mathrm{F}$ of $1982 \mathrm{~L}$ after a single oral dose of netupitant/palonosetron in cancer patients; mean $\mathrm{V}_{\mathrm{z}}$ of $2627 \mathrm{~L}$ after a single IV dose of fosnetupitant/palonosetron), indicating wide distribution throughout the body [6]. At clinically relevant concentrations, netupitant and its major metabolites (see below) are highly (>97\%) bound to plasma proteins $[6,7]$.

Netupitant undergoes extensive metabolism, mediated primarily by CYP3A4 (with smaller contributions from CYP2C9 and CYP2D6), to form three major metabolites (a desmethyl-, an N-oxide- and a hydroxymethyl-derivative), each of which has pharmacological activity $[6,7]$.

Following a single oral dose of netupitant/palonosetron, netupitant has a mean estimated systemic clearance of $\sim 20 \mathrm{~L} / \mathrm{h}$ and an apparent elimination half-life of 80-88 h in cancer patients [6, 7]. Following IV infusion of fosnetupitant/palonosetron, netupitant has a mean total body clearance of $14.1 \mathrm{~L} / \mathrm{h}$ and a terminal half-life of $144 \mathrm{~h}$. Netupitant is primarily excreted via the faeces.

\subsection{Palonosetron Pharmacokinetics}

Following oral administration, palonosetron has an absolute bioavailability of $\sim 97 \%[6,7]$. In cancer patients administered a single oral dose of netupitant/palonosetron, a $\mathrm{C}_{\max }$ for palonosetron of $\sim 0.95 \mathrm{ng} / \mathrm{mL}$ was reached in $\sim 5 \mathrm{~h}$ [6]. Palonosetron exposure is dose proportional over the dose range of $0.25-6.8 \mathrm{mg}$ following single oral doses in healthy subjects. Following IV administration of fosnetupitant/palonosetron in cancer patients, palonosetron reaches a $\mathrm{C}_{\max }$ of $0.8 \mathrm{ng} / \mathrm{mL}$ near the end of the 30-min infusion $[6,7]$.

Palonosetron is widely distributed in the body $\left(\mathrm{V}_{\mathrm{z}} / \mathrm{F}\right.$ of $663 \mathrm{~L}$ after a single oral dose of netupitant/palonosetron in cancer patients; $\mathrm{V}_{\mathrm{z}}$ of $594 \mathrm{~L}$ after a single IV dose of fosnetupitant/palonosetron) [6]. In vitro plasma protein binding was $62 \%[6,7]$.

Approximately half of administered palonosetron is metabolised to two inactive metabolites, $\mathrm{N}$-oxide- and 6-S-hydroxy-palonosetron [6, 7]. In vitro studies indicate that palonosetron metabolism involves CYP2D6 (and to a lesser extent CYP3A4 and CYP1A2), although palonosetron pharmacokinetic parameters are not significantly different between poor and extensive metabolisers of CYP2D6 substrates.

Following oral administration of netupitant/palonosetron in cancer patients, palonosetron has a mean total body clearance of $10.0 \mathrm{~L} / \mathrm{h}$ and a half-life of $50 \mathrm{~h} \mathrm{[6]}$. Following IV infusion of fosnetupitant/palonosetron, palonosetron has a mean total body clearance of $7.6 \mathrm{~L} / \mathrm{h}$ and a terminal half-life of $58 \mathrm{~h}$. Palonosetron is primarily excreted via the urine $[6,7]$.

\subsection{Use in Specific Populations}

No (fos)netupitant/palonosetron dosage adjustment is required in patients with mild to moderate hepatic impairment $[6,7]$. Limited data are available on the use of (fos) netupitant/palonosetron in patients with severe hepatic impairment, and the agent should be used with caution [7] or avoided [6] in these patients.

No (fos)netupitant/palonosetron dosage adjustment is required for use in patients with mild to moderate kidney impairment under the US label [6], or with mild to severe kidney impairment under the EU label [7]. Use of (fos) netupitant/palonosetron should be avoided in patients with severe kidney impairment or end-stage renal disease (ESRD) according to the US label [6], or in patients with ESRD requiring haemodialysis according to the EU label [7].

(Fos)netupitant/palonosetron can be used without dosage adjustment in elderly patients, although caution is advised [6], particularly in patients aged $>75$ years [7].

\subsection{Potential Drug Interactions}

Netupitant is a moderate inhibitor of CYP3A4 and there is the potential for clinically relevant drug interactions between drugs that are metabolised by CYP3A4 and (fos)netupitant/ palonosetron [6, 7]. With its long half-life (Sect. 3.1), netupitant can cause increased exposure to concomitantly administered CYP3A4 substrates for 6 days after a single dose of (fos)netupitant/palonosetron. Given its metabolism by CYP3A4, dexamethasone administered in combination with (fos)netupitant/palonosetron should be used at a reduced dose (see Sect. 6). Also of particular note, patients receiving chemotherapy agents that are primarily metabolised by CYP3A4 (e.g. docetaxel, paclitaxel, etoposide, cyclophosphamide) should be closely monitored for potential adverse events caused by increased exposure to the chemotherapy agent. Co-administration of netupitant/palonosetron with oral contraceptives containing levonorgestrel and ethinyl estradiol had no clinically significant effects on their efficacy [19].

Given the metabolism of netupitant by CYP3A4 (Sect. 3.1), concomitant use of a strong CYP3A4 inducer (e.g. rifampin) can decrease the exposure to and efficacy of (fos)netupitant/palonosetron [6, 7, 19]. Similarly, concomitant use of (fos)netupitant with a strong CYP3A4 inhibitor (e.g. ketoconazole) can increase exposure to the netupitant component of the fixed-dose combination.

In vitro data have shown that (fos)netupitant is an inhibitor of the P-glycoprotein (P-gp) efflux transporter [6, 7]. However, concomitant administration of netupitant and digoxin (a P-gp substrate) did not significantly affect digoxin pharmacokinetics in healthy subjects, and a clinically relevant interaction between (fos)netupitant/palonosetron and 
P-gp substrates in vivo is not expected (although one could be more likely in cancer patients, especially those with kidney function impairment) $[6,7]$.

Local prescribing information should be consulted for full details regarding potential drug interactions involving (fos) netupitant/palonosetron.

\section{Therapeutic Efficacy of NEPA}

Evidence for the efficacy of (fos)netupitant/palonosetron in the prevention of CINV is available from an extensive clinical development programme, including a phase II dose-finding trial (Sect. 4.1.1) and several phase III trials involving both the oral (Sects. 4.1.2, 4.1.3 and 4.1.4) and IV (Sect. 4.2) formulations. The effectiveness of the oral formulation in the real-world setting has also been evaluated in a large, prospective, non-interventional study (Sect. 4.1.5).

In the trials, (fos)netupitant/palonosetron was administered as a single dose before the start of each chemotherapy cycle. Unless otherwise specified, the oral formulation was used as a fixed-dose combination of netupitant/ palonosetron $300 \mathrm{mg} / 0.5 \mathrm{mg}$ and the IV formulation was used as a fixed-dose combination of fosnetupitant/palonosetron $235 \mathrm{mg} / 0.25 \mathrm{mg}$ [17, 20-25]. In addition, all patients received dexamethasone (see Tables 1, 2, 3 and 4 for details). Efficacy was assessed based on patient-reported emetic episodes, nausea severity and rescue medications intake. Key efficacy outcomes included rates of complete response (CR; defined as no emesis and no use of rescue medication), no significant nausea (defined as a maximum score of $<25 \mathrm{~mm}$ on a 0-100 mm visual analogue scale) and complete protection (defined as a CR and no significant nausea). Outcomes were assessed over the acute (hours 0-24), delayed (hours 25-120) and overall (hours 0-120) phases post each chemotherapy cycle.

\subsection{Efficacy of Oral NEPA}

\subsubsection{Phase II Dose-Finding Trial in Patients Receiving HEC}

A randomised, double-blind, multinational, phase II dosefinding trial was conducted to establish the optimal dose of oral netupitant for use with oral palonosetron $0.5 \mathrm{mg}$ in the fixed-dose combination [20]. Included in the trial were chemotherapy-naïve patients $(n=694)$ aged $\geq 18$ years with solid tumours who were scheduled to receive their first course of cisplatin-based HEC. Patients were randomised to receive a single dose of netupitant 100,200 or $300 \mathrm{mg}$ in combination with palonosetron $0.5 \mathrm{mg}$ or a single dose of palonosetron $0.5 \mathrm{mg}$ alone. The trial also included an exploratory arm in which patients received a regimen comprising oral aprepitant for 3 days, a single IV dose of ondansetron, and dexamethasone (see Table 2). The primary endpoint was the $\mathrm{CR}$ rate during the overall phase of chemotherapy cycle 1 . Based on the results of this trial, a fixeddose combination of netupitant/palonosetron $300 \mathrm{mg} / 0.5 \mathrm{mg}$ was selected for evaluation in phase III trials. Data for the netupitant 100 and $200 \mathrm{mg}$ dose groups are not presented or discussed here.

Oral netupitant/palonosetron $300 \mathrm{mg} / 0.5 \mathrm{mg}$ demonstrated good efficacy in the prevention of CINV in patients receiving their first course of cisplatin-based HEC (Table 1) [20]. Compared with patients receiving palonosetron, patients receiving netupitant/palonosetron had a significantly higher CR rate during the overall phase, as well as during the acute and delayed phases, post chemotherapy. Netupitant/ palonosetron was also efficacious in reducing the rates of patients experiencing significant nausea and emesis relative to palonosetron. Rates of complete protection were also higher among netupitant/palonosetron recipients compared with palonosetron recipients (Table 1). Furthermore, efficacy outcomes were similar between patients who received netupitant/palonosetron $300 \mathrm{mg} / 0.5 \mathrm{mg}$ (as a single dose) and those who received the 3-day aprepitant plus ondansetron regimen, with a slight (yet consistent) numerical advantage in favour of netupitant/palonosetron (Table 2); however, no formal comparisons were made between these groups [20].

\subsubsection{Phase III Trial in Patients Receiving AC Chemotherapy}

The efficacy of netupitant/palonosetron versus palonosetron was further evaluated in a randomised, double-blind, multicentre, phase III trial (NCT01339260) in patients $(n=1455)$ receiving their first course of an anthracyclinecyclophosphamide (AC) chemotherapy regimen [22]. In the trial, chemotherapy-naive adults ( $\sim 98 \%$ women $)$ with solid tumours ( $\sim 97 \%$ with breast cancer) were randomised to receive netupitant/palonosetron $300 \mathrm{mg} / 0.5 \mathrm{mg}$ or palonosetron $0.5 \mathrm{mg}$. For approximately two-thirds of patients in the trial, the chemotherapy regimen consisted of doxorubicin plus cyclophosphamide, with the remaining one-third receiving epirubicin plus cyclophosphamide. The primary endpoint of the trial was the CR rate during the delayed phase of chemotherapy cycle 1 .

Similar to the findings of the phase II dose-finding trial in patient receiving HEC (Sect. 4.1.1), oral netupitant/palonosetron was superior to palonosetron in preventing CINV in patients receiving their first course of $\mathrm{AC}$ chemotherapy [22]. CR rates were significantly higher in netupitant/palonosetron recipients than in palonosetron recipients during the acute, delayed and overall phases following cycle 1 of chemotherapy (Table 1). Compared with palonosetron, netupitant/ palonosetron was also associated with significantly higher rates of no emesis, no significant nausea, and complete protection in each of the acute, delayed and overall phases, with 
Table 1 Efficacy of oral NEPA $300 \mathrm{mg} / 0.5 \mathrm{mg}$ versus oral palonosetron $0.5 \mathrm{mg}$ in adult patients receiving a first cycle of chemotherapy

\begin{tabular}{|c|c|c|c|c|}
\hline & Phase II dose & & NCT0133926 & \\
\hline & Cisplatin $(\geq 5$ & $\mathrm{HEC}$ & AC-based ch & \\
\hline & Oral NEPA ${ }^{b}$ & Oral PALO ${ }^{c}$ & Oral NEPA $^{\mathrm{d}}$ & Oral PALO ${ }^{\mathrm{e}}$ \\
\hline & $(n=135)$ & $(n=136)$ & $(n=724)$ & $(n=725)$ \\
\hline Complete respon & of rescue med & & & \\
\hline Acute phase & $98.5^{* *}$ & 89.7 & $88.4 *$ & 85.0 \\
\hline Delayed phase & $90.4^{*}$ & 80.1 & $76.9 * * * \mathrm{f}$ & 69.5 \\
\hline Overall phase & $89.6^{* * \mathrm{f}}$ & 76.5 & $74.3 * * *$ & 66.6 \\
\hline No emesis (\%) & & & & \\
\hline Acute phase & $98.5^{* *}$ & 89.7 & $90.9 *$ & 87.3 \\
\hline Delayed phase & $91.9 * *$ & 80.1 & $81.8 * *$ & 75.6 \\
\hline Overall phase & $91.1 * *$ & 76.5 & $79.8 * * *$ & 72.1 \\
\hline No significant na & $25 \mathrm{~mm}$ on a 10 & alogue scale] & & \\
\hline Acute phase & $98.5^{*}$ & 93.4 & 87.3 & 87.9 \\
\hline Delayed phase & $90.4 * *$ & 80.9 & $76.9 *$ & 71.3 \\
\hline Overall phase & $89.6^{*}$ & 79.4 & $74.6^{*}$ & 69.1 \\
\hline Complete protect & lus no signific & & & \\
\hline Acute phase & $97.0 * *$ & 87.5 & 82.3 & 81.1 \\
\hline Delayed phase & $84.4^{*}$ & 73.5 & $67.3 * *$ & 60.3 \\
\hline Overall phase & $83.0 * *$ & 69.9 & $63.8 *$ & 57.9 \\
\hline
\end{tabular}

NEPA and PALO were administered as single oral doses prior to chemotherapy

$A C$ anthracycline-cyclophosphamide, DEX dexamethasone, $H E C$ highly emetogenic chemotherapy, NEPA netupitant/palonosetron, $P A L O$ palonosetron

$* p \leq 0.05, * * p \leq 0.01, * * * p \leq 0.001$ vs oral PALO

${ }^{a}$ This trial included two further dose-ranging arms (oral NEPA $100 \mathrm{mg} / 0.5 \mathrm{mg}$ and $200 \mathrm{mg} / 0.5 \mathrm{mg}$; data not presented here) as well as an exploratory arm where patients received a standard 3-day aprepitant plus intravenous ondansetron $32 \mathrm{mg}$ regimen (Table 2)

${ }^{\mathrm{b}}$ In addition, patients received oral DEX $12 \mathrm{mg}$ on day 1 and oral DEX $4 \mathrm{mg}$ twice daily on days 2-4

${ }^{\mathrm{c}}$ In addition, patients received oral DEX $20 \mathrm{mg}$ on day 1 and oral DEX $8 \mathrm{mg}$ twice daily on days $2-4$

${ }^{\mathrm{d}}$ In addition, patients received oral DEX $12 \mathrm{mg}$ on day 1

${ }^{\mathrm{e}}$ In addition, patients received oral DEX $20 \mathrm{mg}$ on day 1

${ }^{\mathrm{f}}$ Primary endpoint

the exceptions of no significant nausea and complete protection in the acute phase where between-group differences were non-significant (Table 1).

In an extension to the trial (with $88 \%$ of patients participating) [21], the efficacy of netupitant/palonosetron in preventing CINV was maintained over four cycles of AC chemotherapy, with CR rates and the percentages of patients experiencing no significant nausea significantly higher in netupitant/palonosetron recipients than in palonosetron recipients in the overall phase for each of the cycles (Table 3).

\subsubsection{Phase III Trial in Patients Receiving MEC or HEC}

Further evidence for the efficacy of netupitant/palonosetron in preventing CINV over multiple cycles of chemotherapy is available from a randomised, double-blind, multinational phase III trial (NCT01376297) [23]. Primarily designed to assess safety, this trial evaluated a single oral dose of netupitant/palonosetron $300 \mathrm{mg} / 0.5 \mathrm{mg}$ versus a 3 -day oral regimen of aprepitant (see Table 2 for details) plus a single dose of palonosetron $0.5 \mathrm{mg}$ in chemotherapy-naïve patients $(n=413)$ diagnosed with a malignant tumour and scheduled to receive repeated consecutive courses of HEC or MEC. Patients with breast cancer scheduled to receive AC chemotherapy were excluded. In cycle $1,76 \%$ of patients received MEC (primarily carboplatin or oxaliplatin) and $24 \%$ received HEC (primarily cisplatin). Seventy-five percent of patients in the trial completed at least four cycles of chemotherapy and $40 \%$ completed six cycles [23].

In both antiemetic treatment groups, high overall $\mathrm{CR}$ rates were observed in cycle 1 of chemotherapy (Table 2) and were maintained across multiple cycles (Table 3 ). Although no statistical analyses were reported, a small and consistent 
Table 2 Efficacy of oral NEPA $300 \mathrm{mg} / 0.5 \mathrm{mg}$ versus aprepitant-based regimens in adult patients receiving a first cycle of chemotherapy

\begin{tabular}{|c|c|c|c|c|c|c|}
\hline & Phase II dose & $\operatorname{ding}$ trial $[20]^{\mathrm{a}}$ & NCT013762 & $3,26]$ & Zhang et al. | & \\
\hline & Cisplatin-bas & IEC & $\operatorname{MEC}(76 \%)$ & $\mathrm{EC}(24 \%)$ & Cisplatin-bas & HEC \\
\hline & Oral NEPA ${ }^{b}$ & $\mathrm{APR}+\mathrm{OND}^{\mathrm{b}, \mathrm{c}}$ & Oral NEPA ${ }^{\mathrm{d}}$ & $\mathrm{APR}+\mathrm{PALO}^{\mathrm{d}, \mathrm{e}}$ & Oral NEPA ${ }^{\mathrm{f}}$ & $\mathrm{APR}+\mathrm{GRAN}^{\mathrm{f}, \mathrm{g}}$ \\
\hline & $(n=135)$ & $(n=134)$ & $(n=309)$ & $(n=103)$ & $(n=412)$ & $(n=416)$ \\
\hline Complete respon & and no use of & ue medication] ( & & & & \\
\hline Acute phase & 98.5 & 94.8 & 92.9 & 94.2 & 84.5 & 87.0 \\
\hline Delayed phase & 90.4 & 88.8 & 83.2 & 77.7 & 77.9 & 74.3 \\
\hline Overall phase & 89.6 & 86.6 & 80.6 & 75.7 & 73.8 & 72.4 \\
\hline No emesis $(\%)$ & & & & & & \\
\hline Acute phase & 98.5 & 94.8 & & & 85.2 & 87.5 \\
\hline Delayed phase & 91.9 & 89.6 & & & 79.4 & 76.2 \\
\hline Overall phase & 91.1 & 87.3 & & & 75.0 & 74.0 \\
\hline No significant na & m score $<25$ & on a $100-\mathrm{mm}$ vi & analogue sca & & & \\
\hline Acute phase & 98.5 & 94.0 & 90.6 & 93.2 & 89.8 & 87.3 \\
\hline Delayed phase & 90.4 & 88.1 & 85.1 & 81.6 & 78.2 & 72.8 \\
\hline Overall phase & 89.6 & 85.8 & 84.1 & 80.6 & 75.7 & 70.4 \\
\hline Complete protect & response plus & significant nause & & & & \\
\hline Acute phase & 97.0 & 89.6 & & & & \\
\hline Delayed phase & 84.4 & 82.1 & & & & \\
\hline Overall phase & 83.0 & 78.4 & & & & \\
\hline
\end{tabular}

$A P R$ aprepitant, $D E X$ dexamethasone, GRAN granisetron, $H E C$ highly emetogenic chemotherapy, $I V$ intravenous, $M E C$ moderately emetogenic chemotherapy, NEPA netupitant/palonosetron, $O N D$ ondansetron, $P A L O$ palonosetron

${ }^{a}$ This trial also included two further dose-ranging arms (NEPA $100 \mathrm{mg} / 0.5 \mathrm{mg}$ and NEPA $200 \mathrm{mg} / 0.5 \mathrm{mg}$; data not presented here) as well as an arm where patients received PALO $0.5 \mathrm{mg}$ (see Table 1)

${ }^{\mathrm{b}}$ In addition, patients received oral DEX $12 \mathrm{mg}$ on day 1 and oral DEX $4 \mathrm{mg}$ twice daily on days 2-4

${ }^{\mathrm{c}}$ Oral APR $125 \mathrm{mg}$ plus IV OND $32 \mathrm{mg}$ on day 1 and oral APR $80 \mathrm{mg}$ on days 2-3

${ }^{\mathrm{d}}$ In addition, patients received oral DEX $12 \mathrm{mg}$ on day 1 and patients receiving HEC were also given oral DEX $8 \mathrm{mg} / \mathrm{day}$ on days $2-4$

${ }^{\mathrm{e}}$ Oral APR $125 \mathrm{mg}$ plus oral PALO $0.5 \mathrm{mg}$ on day 1 and oral APR $80 \mathrm{mg}$ on days 2-3

${ }_{\mathrm{f}}^{\mathrm{f}}$ In addition, patients received oral DEX $12 \mathrm{mg}$ on day 1 and oral DEX $8 \mathrm{mg} /$ day on days $2-4$

${ }^{g}$ Oral APR $125 \mathrm{mg}$ plus IV GRAN $3 \mathrm{mg}$ on day 1 and oral APR $80 \mathrm{mg}$ on days 2-3

numerical advantage in overall CR rates was observed for netupitant/palonosetron over the aprepitant plus palonosetron regimen across cycles [23]. In a subgroup analysis, overall CR rates were similar among netupitant/palonosetron-treated patients receiving HEC (79-91\% across cycles) and MEC (80-93\%) [23].

\subsubsection{Phase III Non-Inferiority Trial Versus Aprepitant Plus Granisetron}

The efficacy of netupitant/palonosetron versus aprepitant plus granisetron (i.e. another combination of an NK1 receptor antagonist and a 5- $\mathrm{HT}_{3}$ receptor antagonist) was evaluated in a randomised, double-blind phase III non-inferiority trial conducted in Asia [24]. The trial included chemotherapy-naïve adults who were scheduled to receive their first course of cisplatin-based HEC for the treatment of a solid tumour malignancy. Patients $(n=834)$ were randomised to receive a single oral dose of netupitant/palonosetron $300 \mathrm{mg} / 0.5 \mathrm{mg}$ or a 3-day regimen of oral aprepitant (see Table 2 for details) plus a single IV dose of granisetron $3 \mathrm{mg}$. All patients in the trial were Asian; $81 \%$ were from China, $71 \%$ were male, and lung cancer $(58 \%)$ was the most common malignancy.

In the trial, a single oral dose of netupitant/palonosetron was non-inferior to a 3-day aprepitant plus granisetron regimen, with overall CR rates (primary endpoint) of $73.8 \%$ and $72.4 \%$, respectively (between-group difference $1.5 \%$; $95 \% \mathrm{CI}-4.5$ to $7.5 \%$ ), meeting the margin for noninferiority $(-10 \%)$ [24]. Similar efficacy rates between the two antiemetic treatment groups were also observed in key secondary endpoints, including the CR rate during the acute and delayed phases, and the percentages of patients experiencing no emesis and no significant nausea during the acute, delayed and overall phases (Table 2). Further, whereas daily rates of patients with CINV events 
Table 3 Efficacy of oral NEPA $300 \mathrm{mg} / 0.5 \mathrm{mg}$ over multiple cycles of chemotherapy (overall phase; hours 0-120)

\begin{tabular}{|c|c|c|c|c|c|c|}
\hline \multirow{2}{*}{$\begin{array}{l}\text { Study } \\
\text { Cycle no. (no. of patients for oral } \\
\text { NEPA and control groups) }\end{array}$} & \multicolumn{3}{|c|}{ Complete response $^{\mathrm{a}}(\%)$} & \multicolumn{3}{|c|}{ No significant nausea $(\%)$} \\
\hline & Oral NEPA ${ }^{\mathrm{c}}$ & PALO $^{\mathrm{d}}$ & $\mathrm{APR}+\mathrm{PALO}^{\mathrm{c}, \mathrm{e}}$ & Oral NEPA ${ }^{\mathrm{c}}$ & $\mathrm{PALO}^{\mathrm{d}}$ & $\mathrm{APR}+\mathrm{PALO}^{\mathrm{c}, \mathrm{e}}$ \\
\hline \multicolumn{7}{|c|}{ NCT01339260 (AC-based chemotherapy) $[21,22]^{f}$} \\
\hline Cycle $1(n=724$ and 725$)$ & $74.3 * *$ & 66.6 & & $74.6^{*}$ & 69.1 & \\
\hline Cycle $2(n=635$ and 651$)$ & $80.3^{* * *}$ & 66.7 & & $77.3^{*}$ & 71.6 & \\
\hline Cycle $3(n=598$ and 606) & $83.8 * * *$ & 70.3 & & $78.4^{*}$ & 73.3 & \\
\hline Cycle $4(n=551$ and 560) & $83.8 * * *$ & 74.6 & & $80.2 *$ & 75.2 & \\
\hline \multicolumn{7}{|c|}{ NCT01376297 [MEC (76\%) or HEC $(\mathbf{2 4 \%})][23,26]$} \\
\hline Cycle $1(n=309$ and 103$)$ & 80.6 & & 75.7 & 84.1 & & 80.6 \\
\hline Cycle $2(n=280$ and 96$)$ & 86.1 & & 81.3 & 86.8 & & 86.5 \\
\hline Cycle $3(n=259$ and 90$)$ & 90.7 & & 86.7 & 89.6 & & 83.3 \\
\hline Cycle $4(n=233$ and 81$)$ & 90.1 & & 87.7 & 91.8 & & 86.4 \\
\hline Cycle $5(n=156$ and 57) & 92 & & 86 & NR & & NR \\
\hline Cycle $6(n=124$ and 44$)$ & 91 & & 86 & NR & & NR \\
\hline
\end{tabular}

$A C$ anthracycline-cyclophosphamide, $A P R$ aprepitant, $D E X$ dexamethasone, $H E C$ highly emetogenic chemotherapy, $M E C$ moderately emetogenic chemotherapy, NEPA netupitant/palonosetron, $N R$ not reported, $P A L O$ palonosetron

$* p<0.05, * * p \leq 0.001, * * * p \leq 0.0001$ vs PALO

${ }^{a}$ No emesis and no use of rescue medication

${ }^{\mathrm{b}}$ Maximum score $<25 \mathrm{~mm}$ on a $100-\mathrm{mm}$ visual analogue scale

${ }^{\mathrm{c}}$ In addition, patients received oral DEX $12 \mathrm{mg}$ on day 1; and patients receiving HEC in NCT01376297 were also given oral DEX $8 \mathrm{mg} / \mathrm{day}$ on days 2-4

${ }^{\mathrm{d}}$ Oral PALO $0.5 \mathrm{mg}$ plus oral DEX $20 \mathrm{mg}$ on day 1

${ }^{\mathrm{e}}$ Oral APR $125 \mathrm{mg}$ plus oral PALO $0.5 \mathrm{mg}$ on day 1 and oral APR $80 \mathrm{mg}$ on days $2-3$

${ }^{\mathrm{f}}$ Significance testing prespecified for cycle 1 only; testing post hoc and not adjusted for multiplicity for cycles $2-4$

(i.e. emesis and/or use of rescue medication) were largely stable (between 13\% and 15\%) among patients receiving the aprepitant regimen, a steady numerical decline (from $16 \%$ on day 1 to $8 \%$ on day 5 ) was observed for netupitant/ palonosetron recipients, with the difference between netupitant/palonosetron and aprepitant recipients reaching statistical significance on day 5 ( $8.0 \%$ vs $13.9 \% ; p=0.0063$ ) [24].

\subsubsection{Effectiveness in the Real-World Setting}

Evidence for the effectiveness of oral netupitant/palonosetron in preventing CINV in the real-world setting is available from a prospective, non-interventional study conducted in Germany in 2429 adults receiving HEC or MEC for three cycles [27]. Netupitant/palonosetron was administered according to the EU label (Sect. 6). The primary outcome of the study was quality of life as measured using the Functional Living Index-Emesis (FLIE) questionnaire. Among patients in the full analysis set $(n=2173), 85 \%$ were female, breast cancer (66\%) was the most common cancer type, approximately two-thirds received HEC (predominantly AC) and approximately one-third received MEC (predominantly carboplatin).
In the HEC and MEC groups, respectively, $84-88 \%$ and $82-87 \%$ of patients reported no impact on daily life (NIDL) due to vomiting across cycles $1-3,54-58 \%$ and $59-66 \%$ reported NIDL due to nausea, and $64-66 \%$ and $67-74 \%$ reported NIDL for the combined domain of nausea and vomiting [27]. Overall, high CR rates were also observed across cycles $1-3(89.2-90.9 \%, 86.9-87.1 \%$ and $82.5-83.6 \%$ in the acute, delayed and overall phases, respectively).

\subsection{Efficacy of IV NEPA}

Fosnetupitant $235 \mathrm{mg}$ was shown to be bioequivalent (in terms of exposure) to oral netupitant $300 \mathrm{mg}$ (Sect. 3) [28, 29], and palonosetron $0.25 \mathrm{mg}$ is the recommended IV palonosetron dose (as a bolus administered over $30 \mathrm{~s}$ ) when used as monotherapy for CINV [30, 31]. Furthermore, a randomized, double-blind, phase III non-inferiority trial in chemotherapy-naïve patients $(n=440)$ with solid tumours receiving HEC found that, based on CR rates in the acute phase (primary endpoint), palonosetron $0.25 \mathrm{mg}$ given as a $30-\mathrm{min}$ IV infusion was non-inferior to palonosetron $0.25 \mathrm{mg}$ given as a 30 -second IV bolus [32]. Thus, it was concluded that a palonosetron 0.25 -mg IV infusion was appropriate for use as part of the fosnetupitant/palonosetron IV formulation. 
Table 4 Efficacy of IV and oral NEPA in adult patients receiving cycle 1 of non-AC HEC [17] or AC-based chemotherapy [25] in two phase III trials $^{\mathrm{a}}$

\begin{tabular}{|c|c|c|c|c|}
\hline & NCT02517 & & NCT03403 & \\
\hline & IV NEPA ${ }^{b}$ & Oral NEPA ${ }^{b}$ & IV NEPA $^{\mathrm{c}}$ & Oral NEPA ${ }^{\mathrm{C}}$ \\
\hline No. of patients (full analysis set) & 203 & 201 & 200 & 202 \\
\hline Complete response $^{\mathrm{d}}(\%)$ & & & & \\
\hline Acute phase (hours 0-24) & 92.6 & 90.5 & 86.5 & 88.6 \\
\hline Delayed phase (hours 25-120) & 78.3 & 87.6 & 75.5 & 78.7 \\
\hline Overall phase (hours 0-120) & 76.8 & 84.1 & 73.0 & 77.3 \\
\hline No emesis (overall phase) (\%) & 84.2 & 88.6 & 82.5 & 86.1 \\
\hline No rescue medication (overall phase) (\%) & 82.8 & 89.1 & 81.5 & 86.6 \\
\hline No significant nausea ${ }^{\mathrm{e}}$ (overall phase) $(\%)$ & 79.3 & 86.6 & 70.0 & 74.8 \\
\hline No nausea ${ }^{\mathrm{f}}$ (overall phase) $(\%)$ & NR & NR & 42.0 & 48.0 \\
\hline
\end{tabular}

$A C$ anthracycline-cyclophosphamide, $D E X$ dexamethasone, $H E C$ highly emetogenic chemotherapy, IV intravenous, $N E P A$ (fos)netupitant/palonosetron, $N R$ not reported

${ }^{a}$ The two trials were primarily designed to investigate the safety of the IV NEPA formulation and were not powered to compare the efficacy of the IV and oral NEPA formulations

${ }^{\mathrm{b}}$ In addition to the study drug, all patients received oral DEX $12 \mathrm{mg}$ on day 1 and DEX $8 \mathrm{mg} /$ day on days 2-4

${ }^{\mathrm{c}}$ In addition to the study drug, all patients received oral DEX $12 \mathrm{mg}$ on day 1

${ }^{\mathrm{d}}$ No emesis and no use of rescue medication

${ }^{\mathrm{e}}$ Maximum score $<25 \mathrm{~mm}$ on a $100-\mathrm{mm}$ visual analogue scale

${ }^{\mathrm{f}}$ Maximum score $<5 \mathrm{~mm}$ on a $100-\mathrm{mm}$ visual analogue scale

Evidence for the efficacy of IV fosnetupitant/palonosetron in the prevention of CINV is drawn from two randomised, double-blind, parallel group, multinational phase III trials (NCT02517021 [17] and NCT03403712 [25]), both of which were primarily conducted to evaluate the safety of the IV formulation. The two trials were of similar design, each comparing IV fosnetupitant/palonosetron (administered as a 30-min infusion) with oral netupitant/palonosetron (taken $60 \mathrm{~min}$ before chemotherapy) in chemotherapy-naïve adults. NCT02517021 enrolled adults with solid tumours $(n=404)$ who were scheduled to receive up to four cycles of non-AC HEC (with $96 \%$ of patients receiving cisplatin-based HEC) [17]; NCT03403712 enrolled women with breast cancer $(n=404)$ who were scheduled to receive up to four cycles of AC-based chemotherapy (with $60 \%$ of patients receiving epirubicin plus cyclophosphamide and $40 \%$ receiving doxorubicin plus cyclophosphamide) [25].

Although neither of these studies was designed or powered to evaluate and compare efficacy between the IV and oral (fos)netupitant/palonosetron formulations [17, 25], data from the trials provide good evidence for the efficacy of the IV formulation in the prevention of CINV (Table 4). In cycle 1, overall CR rates in IV and oral (fos)netupitant/ palonosetron recipients, respectively, were $76.8 \%$ and $84.1 \%$ in NCT02517021 and $73.0 \%$ and $77.3 \%$ in NCT03403712. Furthermore, efficacy was sustained in subsequent chemotherapy cycles (Table 5).

\section{Tolerability of NEPA}

(Fos)netupitant/palonosetron is well tolerated based on available evidence, with the safety and tolerability being similar between the oral and IV formulations [17, 20-25, 27, 33]. The fixed-dose combination (administered with concomitant dexamethasone) has been evaluated in controlled clinical trials in patients receiving HEC or MEC (including AC-based and non-AC chemotherapy regimens), and used over single or multiple cycles, with the profile of treatment-emergent adverse events (TEAEs) observed being generally consistent with what would be expected in patient populations receiving chemotherapy [17, 20-25, 33]. Furthermore, a non-interventional study found that the safety and tolerability profile of oral netupitant/palonosetron in the real-world setting was consistent with that observed in clinical trials [27].

In clinical trials, treatment-related adverse events (TRAEs) were reported in 6-15\% of (fos)netupitant/palonosetron recipients, similar to the incidence observed in patient groups receiving palonosetron (without netupitant) or those receiving aprepitant-based regimens [17, 20-25, 33]. In a pooled analysis of patients receiving oral netupitant/palonosetron, the most commonly reported (incidence $\geq 1 \%$ ) TRAEs were headache (3.6\%), constipation (3.0\%) and fatigue (1.2\%) [7]. Across two phase III trials investigating the safety of IV fosnetupitant/palonosetron, infusion-site TEAEs were reported in $2 \%$ of fosnetupitant/palonosetron recipients; no events were considered to be treatment-related [17, 25]. In 
all key clinical trials of (fos)netupitant/palonosetron, serious TRAEs were infrequent (incidence $<1 \%$ where reported) $[17,20-25,33]$. Furthermore, no increase in the incidence, severity or general range of TEAEs was observed when (fos) netupitant/palonosetron was used over multiple (up to four, or more) cycles of chemotherapy [17, 21, 23, 25].

Although some safety concerns have been raised about potential cardiac safety issues associated with $5-\mathrm{HT}_{3}$ receptor antagonists, no significant cardiac safety issues have been identified with (fos)netupitant/palonosetron [17, 20-25]. However, it should be noted that patients with a history of serious cardiovascular disease or predisposition to cardiac conduction abnormalities were excluded from clinical trials. In a randomised, placebo- and positively- (moxifloxacin) controlled thorough QT study in 197 subjects, netupitant/palonosetron was associated with no significant effects on individually heart rate-corrected QT interval, heart rate, PR interval, QRS interval or cardiac morphology, even at supratherapeutic doses $(600 \mathrm{mg}$, not used in clinic) [34]. The development of serotonin syndrome (including fatal cases) has been reported in association with 5 - $\mathrm{HT}_{3}$ receptor antagonists, mostly during concomitant use of serotonergic drugs [6, 7]. Finally, hypersensitivity reactions (including very rare cases of anaphylaxis) have been reported in patients who received palonosetron [6,7].

\section{Dosage and Administration of NEPA}

In the USA, oral netupitant/palonosetron and IV fosnetupitant/palonosetron are each indicated for use in combination with dexamethasone in adults for the prevention of acute and delayed nausea and vomiting associated with initial and repeat courses of cancer chemotherapy [6]. IV fosnetupitant/ palonosetron is approved for use in the prevention nausea and vomiting associated with HEC; oral netupitant/palonosetron is approved for use in the prevention of nausea and vomiting associated with chemotherapy, including, but not limited to, HEC [6]. In the EU, oral netupitant/palonosetron and IV fosnetupitant/palonosetron are each indicated for use in adults for the prevention of acute and delayed nausea and vomiting associated with highly emetogenic cisplatin-based cancer chemotherapy or with MEC [7].

For the oral formulation, one capsule of netupitant/palonosetron $300 \mathrm{mg} / 0.5 \mathrm{mg}$ should be taken (with or without food) approximately $1 \mathrm{~h}$ prior to the start of chemotherapy $[6,7]$. For the IV formulation, one single-dose vial of fosnetupitant/palonosetron $235 \mathrm{mg} / 0.25 \mathrm{mg}$ lyophilised powder should be reconstituted in $50 \mathrm{~mL}$ of $5 \%$ dextrose injection or $0.9 \%$ saline solution for injection and administered as a 30-min infusion starting approximately $30 \mathrm{~min}$ prior to the start of chemotherapy. In the USA, fosnetupitant/palonosetron is also available as a $20-\mathrm{mL}$ solution (in a single-dose vial) which can be added to $30 \mathrm{~mL}$ of $5 \%$ dextrose or $0.9 \%$ saline for
Table 5 Efficacy of IV and oral NEPA in adult patients receiving non-AC HEC [17] or AC-based chemotherapy [25] over multiple cycles in two phase III trials ${ }^{\mathrm{a}}$

\begin{tabular}{lll} 
Study & \multicolumn{2}{l}{ Complete response $^{\mathrm{b}}(\%)$} \\
\hline $\begin{array}{l}\text { Cycle no. (no. of pts for IV and } \\
\text { oral NEPA) }\end{array}$ & IV NEPA & Oral NEPA
\end{tabular}

oral NEPA)

NCT02517021 [17, 28]

Cycle $1(n=203$ and 201$)$

Cycle $2(n=179$ and 176)

$76.8 \quad 84.1$

Cycle $3(n=163$ and 150$)$

79.9

84.1

Cycle $4(n=122$ and 117)

84.0

85.8

NCT03403712 [25]

Cycle $1(n=200$ and 202)

83.6

88.7

Cycle $2(n=193$ and 198)

73.0

97.4

Cycle $3(n=153$ and 157$)$

Cycle 4 ( $n=96$ and 102)

80.3

77.2

8.3

83.4

$A C$ anthracycline-cyclophosphamide, $H E C$ highly emetogenic chemotherapy, IV intravenous, NEPA (fos)netupitant/palonosetron, pts patients

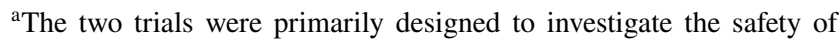
the IV NEPA formulation and were not powered to compare the efficacy of the IV and oral NEPA formulations. In addition to the study drug, all pts received open-label oral dexamethasone (see Table 4)

${ }^{\mathrm{b}}$ No emesis and no use of rescue medication; data shown are for the overall phase (hours $0-120$ post chemotherapy)

infusion as a 50-mL total volume [6]. Given that limited data are available on the compatibility of fosnetupitant/palonosetron with other IV substances (with the exception of IV dexamethasone), other IV substances should not be added to the IV fosnetupitant/palonosetron solution or infused simultaneously [6, 7]. Fosnetupitant/palonosetron is incompatible with any solution containing divalent cations [6, 7].

Based on animal studies, use of (fos)netupitant/palonosetron may be associated with a risk of foetal harm [6, 7], and use of the agent during pregnancy is contraindicated in the EU [7]. Local prescribing information should be consulted for full details regarding the administration of (fos)netupitant/palonosetron, including further information on limitations of use, warnings, precautions, potential drug interactions and use of the agent in specific populations.

\section{Place of NEPA in the Management of CINV}

Combination therapy with drugs targeting different pathways has become the standard-of-care for CINV prophylaxis [2-5]. For patients receiving HEC, current guidelines from the Multinational Association of Supportive Care in Cancer (MASCC)/European Society of Medical Oncology (ESMO) [2], the American Society of Clinical Oncology (ASCO) [3] and the National Comprehensive Cancer Network (NCCN) 
[4] recommend using a four-drug regimen involving olanzapine, an NK1 receptor antagonist, a 5- $\mathrm{HT}_{3}$ receptor antagonist and dexamethasone. According to the MASCC/ESMO guidelines, the inclusion of olanzapine in the regimen is optional but should be considered if nausea is an issue [2]. The NCCN guidelines also recommend as options threedrug combinations of an NK1 receptor antagonist, a 5- $\mathrm{HT}_{3}$ receptor antagonist and dexamethasone, or olanzapine, palonosetron and dexamethasone [4]. For patients receiving MEC, the guidelines generally recommend a two-drug combination of a $5-\mathrm{HT}_{3}$ receptor antagonist and dexamethasone [3-5]. Alternatively, three-drug combinations of olanzapine, palonosetron and dexamethasone, or an NK1 receptor antagonist, a 5- $\mathrm{HT}_{3}$ receptor antagonist and dexamethasone are recommended by the NCCN guidelines for patients with additional patient-related risk factors or patients with previous treatment failure with the recommended two-drug combination [4]. The three-drug combination of an NK1 receptor antagonist, a 5- $\mathrm{HT}_{3}$ receptor antagonist and dexamethasone is also recommended by the MASCC/ESMO and ASCO guidelines for patients receiving carboplatin chemotherapy at any dose [5] or at an area under the curve of $\geq 4 \mathrm{mg} / \mathrm{mL} /$ $\min [3]$.

As a fixed-dose combination of an NK1 receptor antagonist and a 5- $\mathrm{HT}_{3}$ receptor antagonist, (fos)netupitant/palonosetron (used in combination with dexamethasone) aligns well with guideline-recommended prophylaxis against CINV for patients receiving HEC (with the further option of including olanzapine) or for select patients receiving MEC. Furthermore, there is evidence that netupitant and palonosetron act synergistically (Sect. 2). A range of clinical trials has shown that netupitant/palonosetron (plus dexamethasone) has good efficacy in the prevention of CINV (Sect. 4.1). In the key trials, CR rates in the overall phase post chemotherapy cycle 1 were 74-90\%, with efficacy maintained with repeat netupitant/palonosetron doses over multiple cycles of chemotherapy. The netupitant/palonosetron combination was superior to palonosetron in preventing CINV (Sects. 4.1.1 and 4.1.2), and a single oral dose of netupitant/palonosetron was found to be non-inferior to a 3-day aprepitant plus granisetron regimen in patients receiving cisplatin-based HEC (Sect. 4.1.4). Further, a post hoc pooled analysis of the phase II dose-finding trial (Sect. 4.1.1), the phase III trial NCT01376297 (Sect. 4.1.3) and the phase III non-inferiority trial (Sect. 4.1.4) suggested that while netupitant/palonosetron has a similar response rate to a 3-day aprepitant regimen during the acute (day 1) and overall (days 1-5) phases post cisplatin-based chemotherapy, it may be associated with a higher CR rate during the delayed phase (days 2-5) [35]. Overall, the efficacy of netupitant/palonosetron was demonstrated in patients receiving HEC and MEC, including cisplatin-based, AC-based and non-AC regimens. In post hoc pooled subgroup analyses of data from key trials, netupitant/ palonosetron was shown to be efficacious in patients with breast [36], lung [37] and gynaecological cancers [38], and in older patients [39]. Findings from a study of patients in the real-world setting were consistent with data from the key clinical trials (Sect. 4.1.5). Although based on trials that were primarily designed to assess safety, available evidence shows that the more recently developed IV fosnetupitant/ palonosetron fixed-dose combination has similar efficacy to the oral netupitant/palonosetron formulation (Sect. 4.2).

Both the oral and IV formulations of (fos)netupitant/palonosetron are well tolerated, and no increase in the incidence, severity or general range of TEAEs was observed with use of the agent over multiple cycles (Sect. 5). The most commonly reported TRAEs included headache, constipation and fatigue. With the IV formulation, no treatment-related infusion-site reactions were observed in the pivotal trials (Sect. 5). The apparent low risk of infusion-site reactions with fosnetupitant/palonosetron is possibly due to the simplified IV formulation, with fosnetupitant requiring no surfactant, emulsifier or solubility enhancer [17]. Further, it suggests a potential advantage over fosaprepitant, which has been associated with a risk of infusion-site reactions (including some severe reactions) [40].

(Fos)netupitant and palonosetron exhibit complementary pharmacokinetic profiles, with both drugs having long halflives and being widely distributed in the body (Sect. 3) [41]. Furthermore, there appear to be no significant drug-drug interactions between the two components in the fixed-drug combination. There are some other potential drug-drug interactions to be aware of during use of (fos)netupitant/ palonosetron, most notably involving substrates, inducers or inhibitors of CYP3A4 (Sect. 3).

Besides efficacy, safety, tolerability and potential drug interaction considerations, pharmacoeconomic considerations may be important for decisions regarding choice of CINV prophylaxis. In this regard, several pharmacoeconomic analyses have been performed, based on healthcare settings in a variety of countries (including the USA, Germany, Greece, Italy, Mexico and Singapore) comparing netupitant/palonosetron with other combinations of an $\mathrm{NK} 1$ - and a $5-\mathrm{HT}_{3}$ receptor antagonist (all combinations used with dexamethasone) [42-47]. Although the analyses were subject to several limitations, netupitant/palonosetron performed favourably relative to the comparators across the analyses, with pharmacoeconomic benefits of netupitant/ palonosetron primarily arising from a reduction in costs associated with CINV events.

In summary, (fos)netupitant/palonosetron (administered with dexamethasone) is well-tolerated and efficacious in the prevention of acute and delayed CINV in patients receiving HEC or MEC, with tolerability and efficacy maintained over multiple cycles. The fixed-dose combination is concordant with guideline recommendations, and provides a 
simple and convenient option for CINV prophylaxis, targeting two pathways central to the development of nausea and vomiting, both acute and delayed. The availability of the drug combination in oral and IV formulations provides additional convenience, particularly for patients unable to tolerate one or the other route of administration. Administered as a single dose once per chemotherapy cycle, (fos) netupitant/palonosetron minimises any risk of patient noncompliance to CINV prophylaxis, which in turn has the potential to improve adherence to chemotherapy by reducing the impact of CINV. While further head-to-head trials comparing (fos)netupitant/palonosetron with other CINV prophylaxis combinations would be of interest, in conclusion, (fos)netupitant/palonosetron oral and IV formulations provide effective, simple, convenient, guideline-concordant options to consider for prophylaxis against acute and delayed CINV in patients receiving HEC or MEC.

\section{Data Selection—Netupitant/Palonosetron: 286 records identified}

Duplicates removed

Excluded during initial screening (e.g. press releases; news reports; not relevant drug/indication; preclinical study; reviews; case reports; not randomized trial)

Excluded during writing (e.g. reviews; duplicate data; small patient number; nonrandomized/phase I/II trials)

Cited efficacy/tolerability articles

Cited articles not efficacy/tolerability

Search Strategy: EMBASE, MEDLINE and PubMed from 1946 to present. Clinical trial registries/databases and websites were also searched for relevant data. Key words were: Akynzeo, netupitant-palonosetron, fosnetupitant-palonosetron, pro-netupitant-palonosetron, palonosetron-netupitant, palonosetron-fosnetupitant, palonosetron-pro-netupitant. Records were limited to those in English language. Searches last updated 07 June 2021.

Supplementary Information The online version contains supplementary material available at https://doi.org/10.1007/s40265-021-01558-2.

Acknowledgements During the peer review process, the manufacturer of netupitant/palonosetron was also offered an opportunity to review this article. Changes resulting from comments received were made on the basis of scientific and editorial merit.

\section{Declarations}

Funding The preparation of this review was not supported by any external funding.

Authorship and Conflict of interest M. Shirley is a salaried employee of Adis International Ltd/Springer Nature, and declares no relevant conflicts of interest. All authors contributed to the review and are responsible for the article content.

Ethics approval, Consent to participate, Consent to publish, Availability of data and material, Code availability Not applicable.

Open Access This article is licensed under a Creative Commons Attribution-NonCommercial 4.0 International License, which permits any non-commercial use, sharing, adaptation, distribution and reproduction in any medium or format, as long as you give appropriate credit to the original author(s) and the source, provide a link to the Creative Commons licence, and indicate if changes were made. The images or other third party material in this article are included in the article's Creative Commons licence, unless indicated otherwise in a credit line to the material. If material is not included in the article's Creative Commons licence and your intended use is not permitted by statutory regulation or exceeds the permitted use, you will need to obtain permission directly from the copyright holder. To view a copy of this licence, visit http://creativecommons.org/licenses/by-nc/4.0/

\section{References}

1. Adel N. Overview of chemotherapy-induced nausea and vomiting and evidence-based therapies. Am J Manag Care. 2017;23(14 Suppl):S259-65.

2. Herrstedt J, Roila F, Warr D, et al. 2016 Updated MASCC/ESMO consensus recommendations: prevention of nausea and vomiting following high emetic risk chemotherapy. Support Care Cancer. 2017;25(1):277-88.

3. Hesketh PJ, Kris MG, Basch E, et al. Antiemetics: ASCO guideline update. J Clin Oncol. 2020;38(24):2782-97.

4. National Comprehensive Cancer Network. NCCN Clinical Practice Guildelines in Oncology (NCCN Guidelines $\left.{ }^{\circledR}\right)$ : antiemesis (version 1.2021). 2020. https://www.nccn.org. Accessed 24 May 2021.

5. Roila F, Warr D, Hesketh PJ, et al. 2016 updated MASCC/ESMO consensus recommendations: prevention of nausea and vomiting following moderately emetogenic chemotherapy. Support Care Cancer. 2017;25(1):289-94.

6. US FDA. Akynzeo ${ }^{\circledR}$ (netupitant and palonosetron capsules; fosnetupitant and palonosetron for injection; fosnetupitant and palonosetron injection): US prescribing information. 2020. https:// www.fda.gov. Accessed 24 May 2021.

7. European Medicines Agency. Akynzeo: summary of product characteristics 2021. https://www.ema.europa.eu. Accessed 24 May 2021.

8. Keating GM. Netupitant/palonosetron: a review in the prevention of chemotherapy-induced nausea and vomiting. Drugs. 2015;75(18):2131-41.

9. European Medicines Agency. Akynzeo: EPAR—public assessment report. 2015. https://www.ema.europa.eu. Accessed 24 May 2021.

10. Wong EH, Clark R, Leung E, et al. The interaction of RS 25259197, a potent and selective antagonist, with $5-\mathrm{HT}_{3}$ receptors, in vitro. Br J Pharmacol. 1995; 114(4):851-9.

11. Yang LP, Scott LJ. Palonosetron: in the prevention of nausea and vomiting. Drugs. 2009;69(16):2257-78.

12. Rojas C, Stathis M, Thomas AG, et al. Palonosetron exhibits unique molecular interactions with the $5-\mathrm{HT}_{3}$ receptor. Anesth Analg. 2008;107(2):469-78. 
13. Rojas $\mathrm{C}$, Li Y, Zhang J, et al. The antiemetic $5-\mathrm{HT}_{3}$ receptor antagonist palonosetron inhibits substance $\mathrm{P}$-mediated responses in vitro and in vivo. J Pharmacol Exp Ther. 2010;335(2):362-8.

14. Stathis M, Pietra C, Rojas C, et al. Inhibition of substance P-mediated responses in NG108-15 cells by netupitant and palonosetron exhibit synergistic effects. Eur J Pharmacol. 2012;689(1-3):25-30.

15. Thomas AG, Stathis M, Rojas C, et al. Netupitant and palonosetron trigger $\mathrm{NK}_{1}$ receptor internalization in NG108-15 cells. Exp Brain Res. 2014;232(8):2637-44.

16. Rojas $\mathrm{C}$, Thomas AG, Alt $\mathrm{J}$, et al. Palonosetron triggers $5-\mathrm{HT}_{3}$ receptor internalization and causes prolonged inhibition of receptor function. Eur J Pharmacol. 2010;626(2-3):193-9.

17. Schwartzberg L, Roeland E, Andric Z, et al. Phase III safety study of intravenous NEPA: a novel fixed antiemetic combination of fosnetupitant and palonosetron in patients receiving highly emetogenic chemotherapy. Ann Oncol. 2018;29(7):1535-40.

18. Calcagnile S, Lanzarotti C, Gutacker M, et al. Evaluation of the effect of food and age on the pharmacokinetics of oral netupitant and palonosetron in healthy subjects: a randomized, openlabel, crossover phase 1 study. Clin Pharmacol Drug Dev. 2015;4(5):377-86.

19. Calcagnile S, Lanzarotti C, Rossi G, et al. Effect of netupitant, a highly selective $\mathrm{NK}_{1}$ receptor antagonist, on the pharmacokinetics of palonosetron and impact of the fixed dose combination of netupitant and palonosetron when coadministered with ketoconazole, rifampicin, and oral contraceptives. Support Care Cancer. 2013;21(10):2879-87.

20. Hesketh PJ, Rossi G, Rizzi G, et al. Efficacy and safety of NEPA, an oral combination of netupitant and palonosetron, for prevention of chemotherapy-induced nausea and vomiting following highly emetogenic chemotherapy: a randomized dose-ranging pivotal study. Ann Oncol. 2014;25(7):1340-6.

21. Aapro M, Karthaus M, Schwartzberg L, et al. NEPA, a fixed oral combination of netupitant and palonosetron, improves control of chemotherapy-induced nausea and vomiting (CINV) over multiple cycles of chemotherapy: results of a randomized, doubleblind, phase 3 trial versus oral palonosetron. Support Care Cancer. 2017;25(4):1127-35.

22. Aapro M, Rugo H, Rossi G, et al. A randomized phase III study evaluating the efficacy and safety of NEPA, a fixed-dose combination of netupitant and palonosetron, for prevention of chemotherapy-induced nausea and vomiting following moderately emetogenic chemotherapy. Ann Oncol. 2014;25(7):1328-33.

23. Gralla RJ, Bosnjak SM, Hontsa A, et al. A phase III study evaluating the safety and efficacy of NEPA, a fixed-dose combination of netupitant and palonosetron, for prevention of chemotherapyinduced nausea and vomiting over repeated cycles of chemotherapy. Ann Oncol. 2014;25(7):1333-9.

24. Zhang L, Lu S, Feng J, et al. A randomized phase III study evaluating the efficacy of single-dose NEPA, a fixed antiemetic combination of netupitant and palonosetron, versus an aprepitant regimen for prevention of chemotherapy-induced nausea and vomiting (CINV) in patients receiving highly emetogenic chemotherapy (HEC). Ann Oncol. 2018;29(2):452-8.

25. Schwartzberg L, Navari R, Clark-Snow R, et al. Phase IIIb safety and efficacy of intravenous NEPA for prevention of chemotherapy-induced nausea and vomiting (CINV) in patients with breast cancer receiving initial and repeat cycles of anthracycline and cyclophosphamide (AC) chemotherapy. Oncologist. 2020;25(3):e589-97.

26. Schwartzberg L, Karthaus M, Rossi G, et al. Fixed combination of oral NEPA (netupitant-palonosetron) for the prevention of acute and delayed chemotherapy-induced nausea and vomiting in patients receiving multiple cycles of chemotherapy: efficacy data from 2 randomized, double-blind phase III studies. Cancer Med. 2019;8(5):2064-73.

27. Karthaus M, Oskay-Özcelik G, Wülfing P, et al. Real-world evidence of NEPA, netupitant-palonosetron, in chemotherapyinduced nausea and vomiting prevention: effects on quality of life. Future Oncol. 2020;16(14):939-53.

28. European Medicines Agency. Akynzeo: EPAR-assessment report variation. 2020. https://www.ema.europa.eu. Accessed 24 May 2021.

29. US FDA. Akynzeo (fosnetupitant and palonosetron) for injection, for intravenous use: multidiscipline review. 2017. https://www.fda. gov. Accessed 24 May 2021.

30. US FDA. Palonosetron hydrochloride injection, for intravenous use: US prescribing information. 2016. https://www.fda.gov. Accessed 24 May 2021.

31. European Medicines Agency. Aloxi: summary of product characteristics. 2018. https://www.ema.europa.eu. Accessed 24 May 2021.

32. Karthaus M, Szabò P, Voisin D, et al. Phase III study of palonosetron (PALO) given as 30-min IV infusion (IV inf) versus 30-sec IV bolus (IV bol) for prevention of chemotherapy-induced nausea and vomiting (CINV) associated with highly emetogenic chemotherapy (HEC). J Clin Oncol. 2017;35(31 Suppl 1):227.

33. Aapro M, Hesketh PJ, Jordan K, et al. Safety of an oral fixed combination of netupitant and palonosetron (NEPA): pooled data from the phase II/III clinical program. Oncologist. 2016;21(4):494-502.

34. Spinelli T, Moresino C, Baumann S, et al. Effects of combined netupitant and palonosetron (NEPA), a cancer supportive care antiemetic, on the ECG of healthy subjects: an ICH E14 thorough QT trial. Springerplus. 2014;3(389):1-11.

35. Navari RM, Binder G, Bonizzoni E, et al. Single-dose netupitant/palonosetron versus 3-day aprepitant for preventing chemotherapy-induced nausea and vomiting: a pooled analysis. Future Oncol. 2021. https://doi.org/10.2217/fon-2021-0023.

36. Rugo HS, Rossi G, Rizzi G, et al. Efficacy of NEPA (netupitant/ palonosetron) across multiple cycles of chemotherapy in breast cancer patients: a subanalysis from two phase III trials. Breast. 2017;33:76-82.

37. Hesketh PJ, Palmas M, Nicolas P. Preventing chemotherapyinduced nausea and vomiting in patients with lung cancer: efficacy of NEPA (netupitant-palonosetron), the first combination antiemetic. Support Care Cancer. 2018;26(4):1151-9.

38. Bošnjak SM, Stamatovic L, Borroni ME, et al. Efficacy and safety of oral NEPA (netupitant/palonosetron), the first fixedcombination antiemetic, in patients with gynecological cancers receiving platinum-based chemotherapy. Int J Gynecol Cancer. 2018;28(6):1153-61.

39. Aapro M, Jordan K, Gralla RJ, et al. Safety and efficacy of NEPA, an oral fixed combination of netupitant and palonosetron, in older patients. J Geriatr Oncol. 2017;8(1):56-63.

40. US FDA. Emend (fosaprepitant for injection): US prescribing information. 2019. https://www.fda.gov. Accessed 24 May 2021.

41. Gilmore J, Bernareggi A. Complementary pharmacokinetic profiles of netupitant and palonosetron support the rationale for their oral fixed combination for the prevention of chemotherapy-induced nausea and vomiting. J Clin Pharmacol. 2019;59(4):472-87.

42. Botteman M, Nickel K, Corman S, et al. Cost-effectiveness of a fixed combination of netupitant and palonosetron (NEPA) relative to aprepitant plus granisetron (APR + GRAN) for prophylaxis of chemotherapy-induced nausea and vomiting (CINV): a trial-based analysis. Support Care Cancer. 2020;28(2):857-66.

43. Bourhis F, Eriksson J, Ruffo P, et al. NEPA, an oral fixed combination of netupitant and palonosetron, is a cost-effective intervention for the prevention of chemotherapy-induced nausea and vomiting 
(CINV) in Germany and Greece [abstract no. PCN174]. Value Health. 2018;21(Suppl 3):S43-4.

44. Lim SW, Loh KWJ, Boisseau S, et al. Netupitant and palonosetron (NEPA), is a cost-effective intervention for the prevention of chemotherapy-induced nausea and vomiting (CINV) in Singapore [abstract no. PCN206]. Value Health. 2019;22(Suppl 3):S475-6.

45. Park SH, Binder G, Corman S, et al. Budget impact of netupitant/ palonosetron for the prevention of chemotherapy-induced nausea and vomiting. J Med Econ. 2019;22(8):840-7.
46. Restelli U, Saibene G, Nardulli P, et al. Cost-utility and budget impact analyses of the use of NEPA for chemotherapyinduced nausea and vomiting prophylaxis in Italy. BMJ Open. 2017;7(e015645):1-9.

47. Rubio Ponce R, Díaz O, Sinta Cortes G, et al. Economic evaluation of palonosetron/netupitant for the treatment of chemotherapyrelated nausea and vomiting [abstract no. PCN54]. Value Health. 2019;22(Suppl 2):S66. 